\title{
A 47-year-old male with respiratory and renal failure
}

\section{Case report}

A 47-year-old male was admitted with a 5-day history of painful, red, swollen legs, and 48 hours of intermittent sweats and rigors. His only previous medical history was Perthe's disease of the right hip at the age of 8 years. He had no allergies and there was no family history. He was taking ampicillin at a dose of $500 \mathrm{mg}$ t.d.s., as prescribed by his general practitioner. He had a temperature of $39^{\circ} \mathrm{C}$ on admission. Physical examination proved normal, apart from the area of skin over both ankles and the lower right leg, which was swollen, red, hot and tender.

Initial investigations revealed leukocytosis of $15.9 \times 10^{-9}$, neutrophils $11.7 \times 10^{-9}$ and a C-reactive protein level of 70.5 (normal range $0-10$ ). Renal function and serum electrolytes were normal. Chest and ankle radiographs were also normal. Hip radiography revealed changes consistent with old Perthe's disease. Blood cultures were negative. A diagnosis of cellulitis was made by the admitting physicians, and the patient was prescribed intravenous benzylpenicillin and flucloxacillin.

The leukocytosis resolved, but the patient continued to experience a fluctuating temperature. Nine days after admission, he developed non-specific abdominal pains. An ultrasound of the abdomen, kidneys and renal tract proved normal. The next day, he developed a rash on both legs (figure 1).

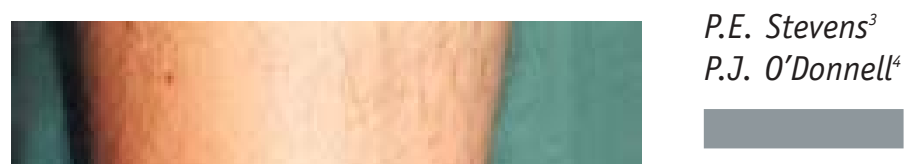

${ }^{1}$ Dept of Respiratory Medicine, Queen Elizabeth the Queen Mother Hospital, Margate, ${ }^{2}$ Dept of Respiratory Medicine, Singleton Hospital, Swansea, ${ }^{3}$ Dept of Renal Medicine, Kent and Canterbury Hospital, Canterbury, and ${ }^{4}$ Dept of Histopathology, St. Thomas' Hospital, London, UK.

\section{Correspondence:}

S. Packham

Dept of Respiratory Medicine

Ward 12, Singleton Hospital Swansea

UK

Fax: 441792285329

E-mail:

Stuart.Packham@swanseatr.wales.nhs.uk
Comment on the skin lesions.
Task 1

Figure 1

Rash observed on the patient's legs. 


\section{Answer 1}

The skin lesions are a vasculitic rash seen predominantly over the extensor surfaces of the patient's legs.

On day 11, the patient developed mild haemoptysis. Chest radiography and a ventilation/perfusion scan were normal. His haemoptysis worsened the following day and he became increasingly breathless. A chest radiograph was repeated (figure 2).

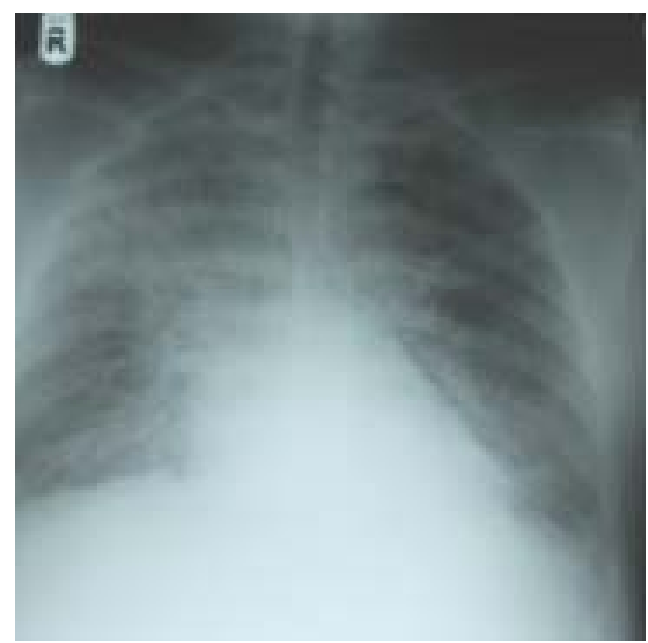

Figure 2

A chest radiograph of the patient on day 12.

\section{Task 2}

Interpret the chest radiograph.

\section{Answer 2}

The chest radiograph shows a widespread bilateral alveolar pattern. The differential diagnosis is wide and may include pulmonary haemorrhage, pulmonary oedema and diffuse atypical pneumonias.

The patient's haemoglobin levels dropped from $12.9 \mathrm{~g} \cdot \mathrm{dL}^{-1}$ to $11.0 \mathrm{~g} \cdot \mathrm{dL}^{-1}$ within 48 hours. The C-reactive protein level at this stage was 263. He did not respond to intravenous diuretics and a subsequent echocardiogram was normal.

The patient developed frank haematuria with casts on day 12 , and his urea and creatinine deteriorated to $17.6 \mathrm{mmol} \cdot \mathrm{L}^{-1}$ and $214 \mathrm{mmol} \cdot \mathrm{L}^{-1}$, respectively, from normal within 48 hours, subsequently peaking at $31.3 \mathrm{mmol} \cdot \mathrm{L}^{-1}$ and 419 $\mu \mathrm{mol} \cdot \mathrm{L}^{-1}$. He showed increasing signs of respiratory distress, with arterial oxygen and carbon dioxide tensions of 9.91 and $5.33 \mathrm{kPa}$, respectively, and pH 7.40 on $15 \mathrm{~L}$ per minute of oxygen, and required intubation and ventilation on day 12. Anti-nuclear cytoplasmic antibody and autoantibody screens were negative, and a glomerular basement membrane antibody screen was 0 (normal range $0-20$ ). Serum complement C3 was $1.53 \mathrm{~g} \cdot \mathrm{L}^{-1}$ (normal range $0.88-2.01$ ) and $\mathrm{C} 4$ was

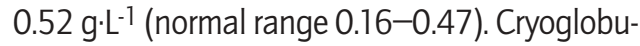
lins were not detected.

Skin and renal biopsies were undertaken, the results of which are shown in figures 3 and 4, respectively.

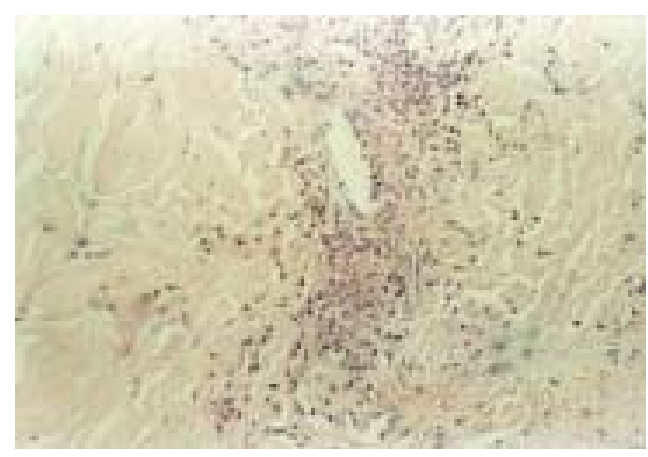

Figure 3

Skin biopsy of the leg rash.

Task 3

Interpret the skin biopsy. 

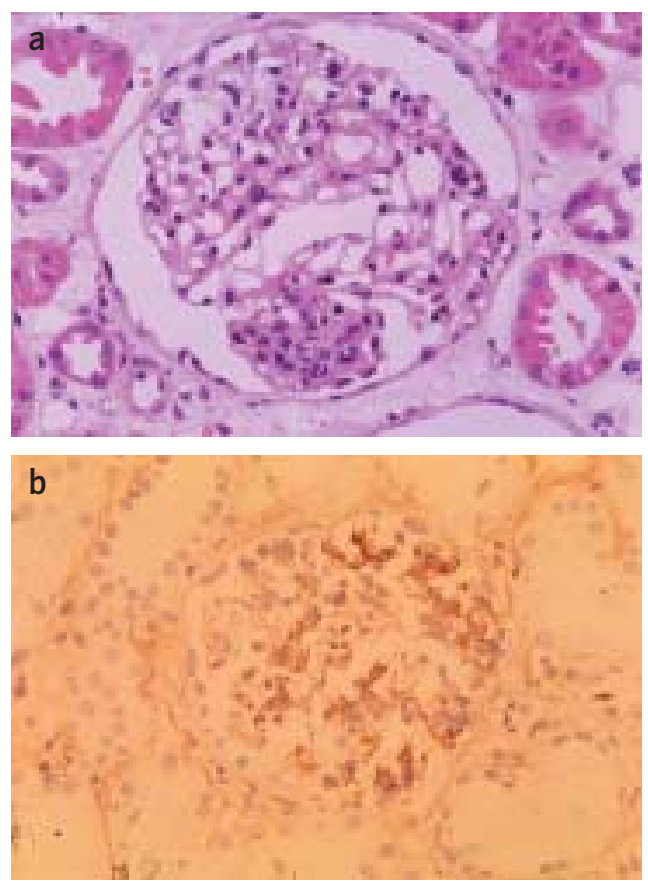

Figure 4

Renal biopsy: a) Haematoxylin and Eosin staining; and b) IgA.

\section{Task 4}

Interpret the renal biopsy.

\section{Answer 3}

The biopsy of his skin rash demonstrates an infiltrate of mainly neutrophil polymorphs in and around the small blood vessels in the upper dermis. There is purpuric extravasation of erythrocytes with fragmented polymorphs and nuclear dust. Small blood vessel walls are acutely inflamed with fibrinoid necrosis and reactive endothelial changes. The changes are consistent with an acute leukocytoclastic cutaneous vasculitis.

\section{Answer 4}

The renal biopsy demonstrates a focal endocapillary proliferative glomerulonephritis superimposed on diffuse mesangial proliferation. There is diffuse staining of the glomerular mesangium and some of the capillary walls with $\lg A$.

The patient was treated with boluses of intravenous methylprednisolone and cyclophosphamide. He was then started on maintenance oral prednisolone and, subsequently, azathioprine. He was extubated on day 21 and discharged home 28 days after admission. One year later, he remains well, with normal renal and lung function, on $5 \mathrm{mg}$ oral prednisolone and 100 mg azathioprine daily.

\section{Task 5}

Suggest a diagnosis for this patient. 


\section{Answer 5}

The diagnosis was Henoch-Schonlein purpura.

\section{Discussion}

Henoch-Schonlein purpura (HSP) is a small vessel vasculitis, characterised by a purpuric rash (typically over the buttocks and legs), arthralgia and abdominal pains [1]. It is more common in children, with a reported incidence of 15 per 100,000 . Pulmonary involvement in children is rare [2]. The reported pulmonary complications are impairment in diffusion capacity of the lungs and pulmonary haemorrhage [3]. Pulmonary haemorrhage usually presents with haemoptysis and/or fleeting pulmonary infiltrates. It occurs more commonly in older children, with an average age of presentation of 12.8 years, compared with 5.8 years without pulmonary haemorrhage.

In adults, pulmonary involvement is even rarer, and several series, including a recent large study of 250 patients with adult-onset HSP and renal involvement, have not identified anyone with respiratory complications $[4,5]$.
Pulmonary-renal syndrome in an adult due to HSP confirmed by histology and immunohistochemistry has only been reported in four patients in the literature, two of whom died and two of whom responded to treatment with prednisolone [6-9]. In addition, two papers have described patients with suspected HSP and pulmonary haemorrhage, but the absence of immunoglobulins and C3 in the mesangium at necropsy cast doubt on the diagnosis in the first case and, in the second, the authors could not demonstrate vasculitis in the lungs [10-12].

There have been no randomised placebo-controlled trials of treatment in adults with HSP. Corticosteroids are the recommended treatment of choice, particularly if there is renal involvement, with treatment initiated as early as possible in the course of the disease. The prognosis for renal involvement is variable, depending on the severity of disease, but up to half of patients can develop renal insufficiency, and cyclophosphamide is often used in addition [13].

In patients with pulmonary involvement resulting in alveolar haemorrhage, case reports suggest a variable prognosis. In view of this early treatment with intravenous corticosteroids, the addition of immunosuppressives and ventilatory support as indicated is recommended.

\section{References}

1. Jennette JC, Falk RJ, Andrassy K, et al. Nomenclature of systemic vasculitides. Proposal of an international consensus conference. Arthritis Rheum 1994; 37: 187-192.

2. Vats KR, Vats A, Kim Y, Dassenko D, Sinaiko AR. Henoch-Schonlein purpura and pulmonary haemorrhage: a report and literature review. Pediatr Nephrol 1999; 13: 530-534.

3. Cream JJ, Gumpel JM, Peachy RDG. Schonlein-Henoch purpura in the adult. A study of 77 adults with anaphylactoid or Schonlein-Henoch purpura. Q J Med 1970; 39: 461-484.

4. Roth DA, Wilz DR, Theil GB. Schonlein-Henoch syndrome in adults. Q J Med 1985; 55: 145-152.

5. Pillebout $E$, Thervet $E$, Hill G, Alberti C, Vanhille P, Nochy D. Henoch-Schonlein purpura in adults: outcome and prognostic factors. J Am Soc Nephrol 2002; 13: 1271-1278.

6. Kathuria S, Cheifec G. Fatal pulmonary Henoch-Schonlein syndrome. Chest 1982; 82: 654-656.

7. McCarthy R, Rosen T, Chen SH, Raimer SS. Adult Henoch-Schonlein purpura with fatal complications. Arch Dermatol 2001; 137: 19-21.

8. Shichiri M, Tsutsumi K, Yamamoto I, Ida T, Iwamoto H. Diffuse intrapulmonary hemorrhage and renal failure in adult Henoch-Schonlein purpura. Am J Nephrol 1987; 7: 140-142.

9. Stienstra Y, Fijen JW, Tervaert JW, et al. Pulmonary haemorrhage with respiratory insufficiency in Henoch-Schonlein purpura. Ned Tijdschr Geneeskd 2000; 144: 617-622.

10. Markus HS, Clark JV. Pulmonary haemorrhage in Henoch-Schonlein purpura. Thorax 1989; 44: 525-526.

11. Veale D, Venning MC, Quinn A. Pulmonary haemorrhage in Henoch-Schonlein purpura (letter). Thorax 1990; $45: 496$.

12. Jacome AF. Pulmonary haemorrhage and death complicating anaphylactoid purpura. South Med J 1967; 60: 1003-1004.

13. Fogazzi GB, Pasquali S, Moriggi M, et al. Long term outcome of Schonlein-Henoch nephritis in the adult. Clin Nephrol 1989; 31: 60-66. 